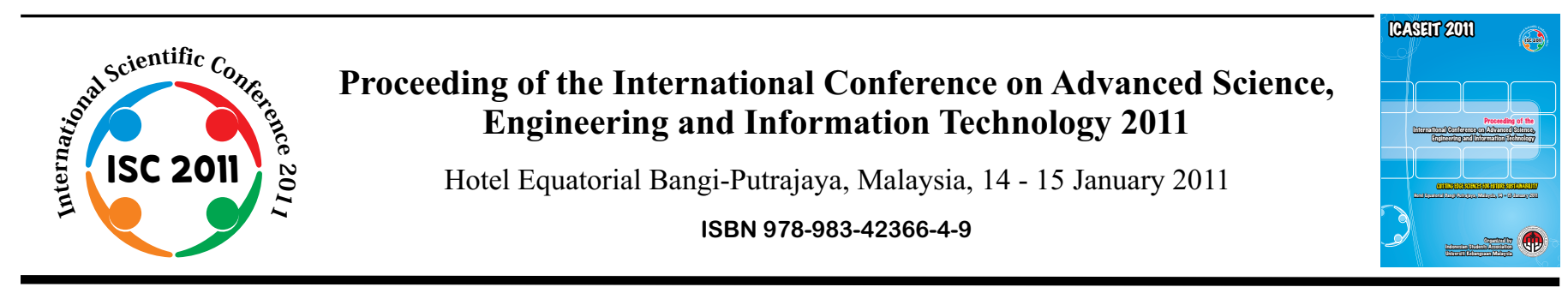

\title{
Influence of Parameters on Usability Attributes in Software Projects
}

\author{
Kshama Paithankar", Maya Ingle* \\ ${ }^{\#}$ Research Scholar, \\ School of Computer Science and Information Technology, DAVV, Indore, 452001, India \\ Tel:+91-731-4010581, paithankars@,rediffmail.com \\ *Professor \& Principal, \\ Indore Institute of Computer Application, Indore, 453331, India \\ Tel:+91-731-4010580, maya ingle@rediffmail.com
}

\begin{abstract}
To attain certain level of usability, a variety of criteria may be used related to a software project. These criteria are involved with intent of driving various factors associated with software development. These criteria are termed as project parameters. It has been observed that these parameters may influence different attributes associated with software projects thereby indulge with the same instinct for usability attributes also. However, the involvement of these parameters may be mounded in such a way that may lead to characterize the projects more specifically in usability perspective. For the same reason, it is needed to provide measures for characterizing projects. Therefore, an empirical method is proposed for estimation of influence of project parameters on associated usability attributes in a software project in this paper. It will provide quantitative measures related to software projects which in turn will be useful for ranking usability attributes. Usability measurement may also be performed subsequently.
\end{abstract}

Keywords — Usability, Usability Attributes, Project, Project Parameters, Project Influence.

\section{INTRODUCTION}

There may exist various criteria to evaluate the software projects for arriving at certain level of usability. While developing a project, different parameters may be used as drivers concerned with distinct factors and involved at different stages of software development project [1, 2, 3]. It has been observed that as parameter values are entered or changed, it updates the cost and effort estimates in realtime to determine the impact on a project's ultimate outcome [4]. Possessing very important functional characteristics, usability attributes are associated with parameters of software project and involved in the development activity of the project. Further, it has been noticed that these usability attributes hold typical dependencies on various project parameters $[5,6,7,8,9$, 10]. Thus, these parameters may have influence on the usability attributes. It may result in varying impact of these attributes in software development projects. However, it is required to provide means to assess the influence of the project parameters on the attributes of usability and the measures of impact of usability attributes in projects at the same time. Therefore, we propose an empirical method for assessment of influence of project parameters on usability attributes in this paper.

Since project parameters dominate the impact of usability attributes and used to characterize software projects, some basic project parameters are reviewed and new terms required for the influence assessment are defined in Section II in this paper. Section III deals with steps involved in proposed influence assessment method $I A M$. In Section IV, case study is presented executing IAM. The observations on results are presented in Section V. Finally, we conclude with the usefulness of the proposed method in Section VI.

\section{TERMINOLOGY}

We define some existing fundamental project parameters such as project size, project type, and development approach used in this section. Further, some new terms are defined based upon aforesaid existing project parameters 
that are required to assess influence of these parameters on usability attributes.

\section{Project Size}

It is defined as number of lines of source code (LOC) in the software and is denoted as $S$. There may exist various kinds of size based upon LOC. Thus, $S_{\mathrm{i}}, \mathrm{i}=1, \ldots, \mathrm{p}$; represent $\mathrm{p}$ kinds of project size of interest.

\section{Project Type}

It pertains to the software development, using some specific criteria and is denoted by $T$. There may exist $\mathrm{q}$ kinds of a project type such as $T_{\mathrm{j}}, \mathrm{j}=1, \ldots, \mathrm{q}$.

\section{Project Development Approach}

It is concerned with the environment in which the software is developed and is represented by $D$. Various kinds of approaches such as $D_{\mathrm{k}}, \mathrm{k}=1, \ldots, \mathrm{r}$; may be used for software development.

In general, a software project is characterized broadly with parameters $S_{\mathrm{i}}, T_{\mathrm{j}}$, and $D_{\mathrm{k}}$ and is denoted by $S_{\mathrm{i}} T_{\mathrm{j}} D_{\mathrm{k}}$.

\section{Usability Attributes}

Usability attributes are highly concerned with the development of software. In other words, these attributes are treated as the functional characteristics associated with the software. Also, these attributes may be dealt as the means to determine the extent of usability of software [11].

\section{Level of Influence}

It is a qualitative measure and is defined as the impact of any kind of parameter of a project $S_{\mathrm{i}} T_{\mathrm{j}} D_{\mathrm{k}}$ on the usability attributes associated with the same software project. Levels of influence of a parameter on a usability attribute may be denoted by $I_{\mathrm{m}}, \mathrm{m}=1, \ldots, \mathrm{v}$; where $\mathrm{v}$ denotes the number of levels of influence assumed in developing a software project. Each level of influence is mapped quantitatively with weights in such a manner that sum of the weights should be 1 .

\section{Project Influence (PI)}

It refers to the overall influence of kinds of parameters on a usability attribute in a project and is denoted by PI. It is computed as the sum of weights assigned to influence levels of kinds of parameters of interest in a given project associated with usability attribute $A_{\mathrm{n}}$. Thus,

$$
0 \leq P I\left(S_{\mathrm{i}} T_{\mathrm{j}} D_{\mathrm{k}}, A_{\mathrm{n}}\right) \leq \theta \cdot \mathrm{W}_{\max }
$$

where $\theta$ stands for number of parameters of interest in a domain of projects and $\mathrm{W}_{\max }$ is maximum of weights of influence levels.

\section{INFLUENCE ASSESSMENT METHOD (IAM)}

We propose a method IAM that requires a domain of projects with a variety of parameters for assessing the overall influence of various kinds of parameters on usability attributes. The stepwise description of $I A M$ is as follows:
Step I: Identification of mutually exclusive projects.

It is required to identify the mutually exclusive (distinct) projects in a domain of projects. Considering three fundamental parameters (viz. project size, project type and development approach) of any software project $S_{\mathrm{i}} T_{\mathrm{j}} D_{\mathrm{k}}$, there exist $\mathrm{p}^{*} \mathrm{q}^{*} \mathrm{r}$ possible mutually exclusive projects in our project domain.

\section{Step II: Identification of level of influence and weights.}

One must estimate the number of influence levels $\mathrm{v}$ and then subsequently identify the influence levels $I_{\mathrm{m}}$, $\mathrm{m}=1, \ldots, \mathrm{v}$ as per the requirements and scope of a domain of projects. At the same time, it is required to assign weights to each of these influence levels heuristically in such a manner that their sum is equal to 1 .

\section{Step III: Assessment of influence levels of parameters on} usability attributes.

A thorough study must be carried out for assessing the influence level of each kind of parameter on a specific usability attribute. The behavior of every concerned usability attribute is investigated with respect to each kind of parameter in a domain of projects. On the basis of this study, these behaviors may be scaled using some suitable mechanism and accordingly the levels of influence may be decided and allocated to various kinds of parameters on usability attributes.

\section{Step IV: Allocation of weights.}

With respect to each level of influence, proper weights are to be mapped. Corresponding to the levels of influence $I_{1}, I_{2}, I_{3}$ and $I_{4}$, weights are mapped. Respectively, the weights are allocated to each kind of parameter on all concerned usability attributes in a domain of projects. Allocation of weights is performed based on the assessed influence levels of project parameters on usability attributes.

Step V: Assessment of influence on usability attributes in a domain of projects.

On the basis of the weights assigned, now it becomes possible to compute overall influence of project parameters on each of the usability attributes using $\operatorname{PI}\left(S_{\mathrm{i}} T_{\mathrm{j}} D_{\mathrm{k}}, A_{\mathrm{n}}\right)$ in each of the project $S_{\mathrm{i}} T_{\mathrm{j}} D_{\mathrm{k}}, \mathrm{i}=1, \ldots, \mathrm{p} ; \mathrm{j}=1, \ldots, \mathrm{q} ; \mathrm{k}=1, \ldots, \mathrm{r}$ as defined earlier.

\section{CASE STUDY}

Here, twenty four projects with three parameters as size, type and development approach have been taken for experimentation. The kinds of the projects with kinds of size are small $\left(S_{1}\right)$, intermediate $\left(S_{2}\right)$, medium $\left(S_{3}\right)$ and large $\left(S_{4}\right)$; kinds of type as organic $\left(T_{1}\right)$, semidetached $\left(T_{2}\right)$ and embedded $\left(T_{3}\right)$; developed using procedure oriented approach $\left(D_{1}\right)$ and object oriented approach $\left(D_{2}\right)$. The usability attributes of our interest are access control $\left(A_{1}\right)$, adaptability $\left(A_{2}\right)$, affect $\left(A_{3}\right)$, customizability $\left(A_{4}\right)$, efficiency $\left(A_{5}\right)$, helpfulness $\left(A_{6}\right)$, learnability $\left(A_{7}\right)$, 
operability $\left(A_{8}\right)$, practicability $\left(A_{9}\right)$, resilience $\left(A_{10}\right)$, un-ambiguity $\left(A_{11}\right)$ and validity $\left(A_{12}\right)$.

It is observed during the rigorous study of various projects that the functional characteristics of usability attributes affect the degree of dependency on parameters. We have examined the dependencies of each usability attribute on each of the kinds of parameters in exhaustive manner and developed a four-tiered structure for the levels of influence ranging from insignificant to significant. A mechanism is used to record this behavior of usability attributes in terms of sequence of stars $(*)$ and hence the level of significance also. Here, '****, denotes insignificant level $\left(I_{1}\right)$, '***' moderate $\left(I_{2}\right)$, '**' average $\left(I_{3}\right)$ and ' $*$ ' refers to the significant level of influence $\left(I_{4}\right)$ respectively of project parameters on usability attributes in a domain of projects. The weights may be associated with these levels of significances either in ascending/ descending order. We explain computation of $P I$ using IAM as follows:

Initially, the weights are assigned in increasing order of magnitude corresponding to four levels of significances such as insignificant, moderate, average and significant respectively. There remain many ways termed as schemes to map weights with influence levels in increasing order in such a manner that their sum equals 1 . Our study includes weights of scheme $(0.1,0.2,0.3,0.4)$ for assessment of project influence. We now map these weights to the influence levels of the parameters and assign these weights to kinds of parameters on usability attributes as shown in Table-1.

Once the weights are allocated to kinds of project parameters in a domain of projects, overall influence of project parameters may be estimated on usability attributes in different projects. For example, the project influence of $S_{2}, T_{2}$ and $D_{2}$, on usability attribute validity, in a project $S_{2} T_{2} D_{2}$ is computed as

$$
P I\left(S_{2} T_{2} D_{2}, \text { validity }\right)=0.2+0.2+0.4=0.8
$$

and is highlighted in Table-2. Proceeding in the similar manner, project influence of kinds of parameters associated with validity in all twenty four projects is evaluated using the weights assigned to levels of influences shown in Table-1. The project influences of kinds of parameters on each of the other usability attributes estimated in different projects are shown in Table-2. It has been observed in all projects $S_{\mathrm{i}} T_{\mathrm{j}} D_{\mathrm{k}}, \mathrm{i}=1, \ldots, \mathrm{p} ; \mathrm{j}=1, \ldots, \mathrm{q} ; \mathrm{k}=1, \ldots, \mathrm{r}$ that $0.3 \leq P I\left(S_{\mathrm{i}}, T_{\mathrm{j},}, D_{\mathrm{k}}, A_{\mathrm{n}}\right) \leq 1.2$,

with 3 parameters and $\mathrm{W}_{\max }=\max (0.1,0.2,0.3,0.4)=0.4$

Table-1: Assessment of Influence Levels and Weights

\begin{tabular}{|c|c|c|c|c|c|c|c|c|c|}
\hline \multirow{2}{*}{$\underbrace{\text { Parameters }}_{\text {Attributes }}$} & \multicolumn{4}{|c|}{ Size } & \multicolumn{3}{|c|}{ Type } & \multicolumn{2}{|c|}{ Development Approach } \\
\hline & $S_{1}$ & $S_{2}$ & $S_{3}$ & $S_{4}$ & $T_{1}$ & $T_{2}$ & $T_{3}$ & $D_{1}$ & $D_{2}$ \\
\hline \multirow[t]{2}{*}{ Access Control } & $* * * *$ & $* * * *$ & $* * *$ & $* *$ & **** & $* * *$ & * & $* *$ & $* * *$ \\
\hline & 0.1 & 0.1 & 0.2 & 0.3 & 0.1 & 0.2 & 0.4 & 0.3 & 0.2 \\
\hline \multirow[t]{2}{*}{ Adaptability } & $* * * *$ & $* * * *$ & $* *$ & $*$ & ***** & $* *$ & $*$ & $*$ & $*$ \\
\hline & 0.1 & 0.1 & 0.3 & 0.4 & 0.1 & 0.3 & 0.4 & 0.4 & 0.4 \\
\hline \multirow[t]{2}{*}{ Affect } & **** & $* * * *$ & $* * *$ & $* * * *$ & $* * * *$ & $* *$ & $*$ & $* * *$ & $* * *$ \\
\hline & 0.1 & 0.1 & 0.2 & 0.2 & 0.1 & 0.3 & 0.4 & 0.2 & 0.2 \\
\hline \multirow[t]{2}{*}{ Customizability } & $* * * *$ & $* * *$ & ** & $*$ & $* * *$ & $* *$ & $*$ & $* *$ & $* *$ \\
\hline & 0.1 & 0.2 & 0.3 & 0.4 & 0.2 & 0.3 & 0.4 & 0.3 & 0.3 \\
\hline \multirow[t]{2}{*}{ Efficiency } & ***** & $* * *$ & $* *$ & $* *$ & $* * * *$ & $* *$ & $*$ & $* *$ & $* *$ \\
\hline & 0.1 & 0.2 & 0.3 & 0.3 & 0.1 & 0.3 & 0.4 & 0.3 & 0.3 \\
\hline \multirow[t]{2}{*}{ Helpfulness } & ***** & $* * *$ & $* *$ & $*$ & $* *$ & $*$ & $*$ & $*$ & ** \\
\hline & 0.1 & 0.2 & 0.3 & 0.4 & 0.3 & 0.4 & 0.4 & 0.4 & 0.3 \\
\hline \multirow[t]{2}{*}{ Learnability } & $* * * *$ & $* * * *$ & $* * *$ & $* *$ & $* * * *$ & $* * *$ & $* *$ & $* * *$ & $* * *$ \\
\hline & 0.1 & 0.1 & 0.2 & 0.3 & 0.1 & 0.2 & 0.3 & 0.2 & 0.2 \\
\hline \multirow{2}{*}{ Operability } & $* * * *$ & $* * * *$ & $* * *$ & $* *$ & $* * * *$ & $* * *$ & $* * *$ & $* * *$ & $* * *$ \\
\hline & 0.1 & 0.1 & 0.2 & 0.3 & 0.1 & 0.2 & 0.2 & 0.2 & 0.2 \\
\hline \multirow[t]{2}{*}{ Practicability } & $* * * *$ & $* * * *$ & $* * * *$ & $* * * *$ & $* * * *$ & $* * * *$ & $* * * *$ & $* * * *$ & $* * * *$ \\
\hline & 0.1 & 0.1 & 0.1 & 0.1 & 0.1 & 0.1 & 0.1 & 0.1 & 0.1 \\
\hline \multirow{2}{*}{ Resilience } & $*$ & $*$ & $*$ & $*$ & $*$ & $*$ & $*$ & $*$ & $*$ \\
\hline & 0.4 & 0.4 & 0.4 & 0.4 & 0.4 & 0.4 & 0.4 & 0.4 & 0.4 \\
\hline \multirow{2}{*}{ Un-ambiguity } & $* * * *$ & $* * * *$ & $* *$ & $*$ & $* * *$ & $* *$ & $*$ & $* * *$ & $* * *$ \\
\hline & 0.1 & 0.1 & 0.3 & 0.4 & 0.2 & 0.3 & 0.4 & 0.2 & 0.2 \\
\hline \multirow[t]{2}{*}{ Validity } & $* * * *$ & $* * *$ & $* *$ & $*$ & $* * *$ & $* * *$ & $* * *$ & $*$ & $*$ \\
\hline & 0.1 & 0.2 & 0.3 & 0.4 & 0.2 & 0.2 & 0.2 & 0.4 & 0.4 \\
\hline
\end{tabular}


Table-2: Project Influence of Project Parameters on Usability Attributes

\begin{tabular}{|c|c|c|c|c|c|c|c|c|c|c|c|c|}
\hline $\begin{array}{c}\text { Attributes } \\
\text { Projects }\end{array}$ & $\mathbf{A}_{1}$ & $\overline{\mathbf{A}_{2}}$ & $\overline{A_{3}}$ & $\mathbf{A}_{4}$ & $\overline{A_{5}}$ & $\mathbf{A}_{6}$ & $\mathbf{A}_{7}$ & $\mathbf{A}_{8}$ & $\mathbf{A}_{9}$ & $\mathbf{A}_{10}$ & $\mathbf{A}_{11}$ & $\mathbf{A}_{12}$ \\
\hline$S_{1} T_{1} D_{1}$ & .5 & .6 & .4 & .6 & .5 & .8 & .4 & .4 & .3 & 1.2 & .5 & .7 \\
\hline$S_{1} T_{1} D_{2}$ & .4 & .6 & .4 & .5 & .5 & .7 & .4 & .4 & .3 & 1.2 & .5 & .7 \\
\hline$S_{1} T_{2} D_{1}$ & .6 & .8 & .6 & .7 & .7 & .9 & .5 & .5 & .3 & 1.2 & .6 & .7 \\
\hline$S_{1} T_{2} D_{2}$ & .5 & .8 & .6 & .7 & .7 & .8 & .5 & .5 & .3 & 1.2 & .6 & .7 \\
\hline$S_{1} T_{3} D_{1}$ & .8 & .9 & .7 & .8 & .8 & .9 & .6 & .5 & .3 & 1.2 & .7 & .7 \\
\hline$S_{1} T_{3} D_{2}$ & .7 & .9 & .7 & .8 & .8 & .8 & .6 & .5 & .3 & 1.2 & .7 & .7 \\
\hline$S_{2} T_{1} D_{1}$ & .5 & .6 & .4 & .7 & .6 & .9 & .4 & .4 & .3 & 1.2 & .5 & .8 \\
\hline$S_{2} T_{1} D_{2}$ & .4 & .6 & .4 & .7 & .6 & .8 & .4 & .4 & .3 & 1.2 & .5 & .8 \\
\hline$S_{2} T_{2} D_{1}$ & .6 & .8 & .6 & .8 & .8 & 1.0 & .5 & .5 & .3 & 1.2 & .6 & .8 \\
\hline$S_{2} T_{2} D_{2}$ & .5 & .8 & .6 & .8 & .8 & .9 & .5 & .5 & .3 & 1.2 & .6 & .8 \\
\hline$S_{2} T_{3} D_{1}$ & .8 & .9 & .7 & .9 & .9 & 1.0 & .6 & .5 & .3 & 1.2 & .7 & .8 \\
\hline$S_{2} T_{3} D_{2}$ & .7 & .9 & .7 & .9 & .9 & .9 & .6 & .5 & .3 & 1.2 & .7 & .8 \\
\hline$S_{3} \mathrm{~T}_{1} \mathrm{D}_{1}$ & .6 & .8 & .5 & .8 & .7 & 1.0 & .5 & .5 & .3 & 1.2 & .7 & .9 \\
\hline$S_{3} T_{1} D_{2}$ & .5 & .8 & .5 & .8 & .7 & .9 & .5 & .5 & .3 & 1.2 & .8 & .9 \\
\hline$S_{3} \mathrm{~T}_{2} \mathrm{D}_{1}$ & .7 & 1.0 & .7 & .9 & .9 & 1.1 & .6 & .6 & .3 & 1.2 & .8 & .9 \\
\hline$S_{3} T_{2} D_{2}$ & .6 & 1.0 & .7 & .9 & .9 & 1.0 & .6 & .6 & .3 & 1.2 & .8 & .8 \\
\hline$S_{3} T_{3} D_{1}$ & .9 & 1.1 & .8 & .1 .0 & 1.0 & 1.1 & .7 & .6 & .3 & 1.2 & .9 & .9 \\
\hline$S_{3} T_{3} D_{2}$ & .8 & 1.1 & .8 & 1.0 & 1.0 & 1.0 & .7 & .6 & .3 & 1.2 & .9 & .9 \\
\hline$S_{4} T_{1} D_{1}$ & .7 & .9 & .5 & .9 & .7 & 1.1 & .6 & .6 & .3 & 1.2 & .8 & 1.0 \\
\hline$S_{4} T_{1} D_{2}$ & .6 & .9 & .5 & .9 & .7 & 1.0 & .6 & .6 & .3 & 1.2 & .8 & 1.0 \\
\hline$S_{4} T_{2} D_{1}$ & .8 & 1.1 & .7 & 1.0 & .9 & 1.2 & .7 & .7 & .3 & 1.2 & .9 & 1.0 \\
\hline$S_{4} T_{2} D_{2}$ & .8 & 1.2 & .7 & 1.0 & .9 & 1.1 & .7 & .7 & .3 & 1.2 & .9 & 1.0 \\
\hline$S_{4} T_{3} D_{1}$ & 1.0 & 1.2 & .8 & 1.1 & 1.0 & 1.2 & .8 & .7 & .3 & 1.2 & 1.0 & 1.0 \\
\hline$S_{4} T_{3} D_{2}$ & .9 & 1.2 & .8 & 1.1 & 1.0 & 1.1 & .8 & .7 & .3 & 1.2 & 1.0 & 1.2 \\
\hline
\end{tabular}

\section{RESULTS}

With the help of case study, the performance of IAM has been examined on the basis of influence of project parameters on usability attributes. Some observations are as follows:

a. It has been observed that lower the value of $P I$ on any usability attribute causes higher the impact. Thus, $P I$ on practicability having lowest value as .3 attains its highest impact whereas PI on resilience possesses always highest value as 1.2 meaning that resilience imposes lowest impact in all the projects.

b. Each attribute imposes its varying influence in various software projects as shown in Fig.-1 thereby showing its importance accordingly. For instance, PI on adaptability has been observed as .4, .6, .7, .9 and 1.0 in distinct projects $S_{1} T_{1} D_{2}, S_{2} T_{2} D_{1}, S_{2} T_{3} D_{2}, S_{3} T_{3} D_{1}$ and $S_{4} T_{3} D_{1}$ respectively.

c. The $P I$ of a software project on usability attributes varies as the size, type and development approach changes and is depicted in Fig.-2. The average PI on usability attributes in projects with sizes $S_{1}, S_{2}, S_{3}$ and $S_{4}$ is estimated as $.65, .69, .79$ and .86 respectively. Similarly, in projects with different types $T_{1}, T_{2}$ and $T_{3}$ average $P I$ on usability attributes is assessed as $.65, .76$ and .82 correspondingly. Equally, with change in development approach from $D_{1}$ to $D_{2}$ results in $P I$ as .76 and .74 accordingly.

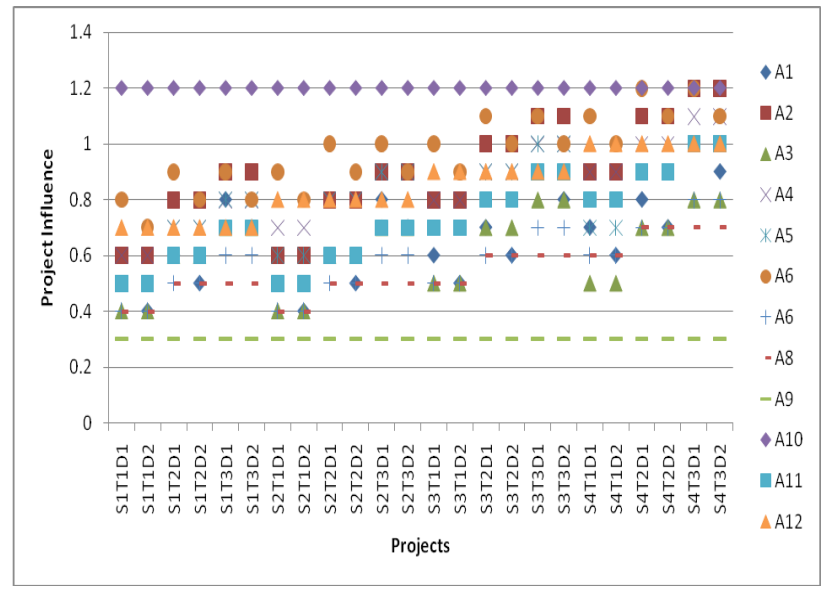

Fig.-1: Project Influence on Usability Attributes in Projects

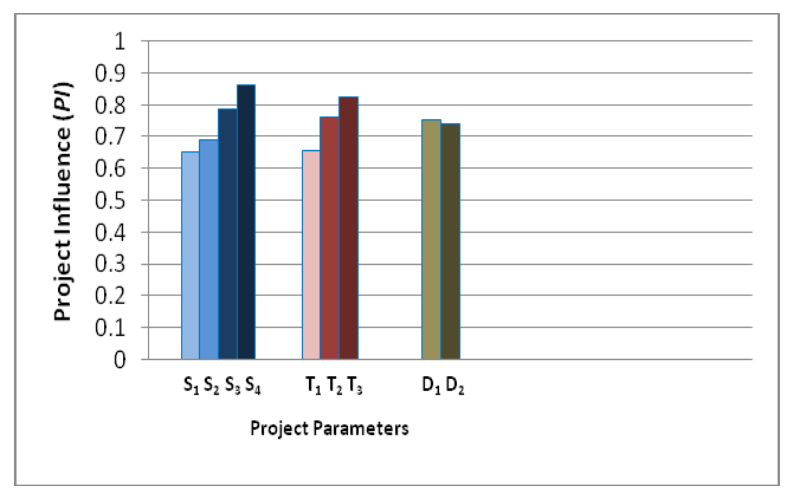

Fig.-2: Varying PI with Change of Project Patameters 


\section{VI.CONCLUSION}

We have proposed a method IAM for assessing the project influence on various usability attributes. It has been noticed that the influence of kinds of parameters on each usability attribute varies in software project. Thus, the weights corresponding to these levels are assigned to the kinds of parameters associated with each of the usability attributes accordingly. IAM provides quantitative measures of the influence of project parameters on usability attributes in different projects. The results will be useful for ranking usability attributes. Also, it may help to provide usability measurement subsequently.

\section{REFERENCES}

[1] Paithankar, K. and Ingle, M., Characterization of Software Projects by Restructuring Parameters for Usability Evaluation, Proceedings of the $2^{\text {nd }}$ international conference on computer and electrical engineering (ICCEE 2009), Dubai, UAE, December 28-30, 2009, pp 438-443.

[2] Yourdon, E., Software Metrics, Application Development Strategies, November 1994, Volume 6, Issue 11, pp1-16.

[3] Fenton, N., Software Measurement: A necessary Scientific Basis, IEEE Transactions of Software Engineering, March 1994,Volume 20, Issue 3, pp 199-206.
[4] Adikari, S. M. C., User and Usability Modeling for HCI, International Conference on Information and Automation. ICIA 2006, December 15-17, 2006, pp 151-154.

[5] Haas, P. J., Hueske, F. and Markl, V., Detecting Attribute Dependencies from Query Feedback, Proceedings of the $33^{\text {rd }}$ international conference on Very large data bases, Austria, 2007, pp 830-841.

[6] Sandhu, P. S., Blecharz, P. and Singh, H., A Taguchi Approach to Investigate Impact of Factors for Reusability of Software Components, Journal of World Academy Of Science, Engineering And Technology, 2007, Volume 25, pp 135-140.

[7] Peischl B., Nica, M. and Zanker, M., Recommending effort estimation methods for software project management, IEEE/WIC/ACM International Joint Conference on Web Intelligence and Intelligent Agent Technology, 2009, Volume 03, pp 77-80.

[8] Jiang, Z., Naudé, P and Jiang, B., The Effects of Software Size on Development Effort and Software Quality, World Academy of Science, Engineering and Technology, 2007, Volume 34, pp 31-35.

[9] Perepletchikov, M., Ryan, C. and Tari , Z., The Impact of Software Development Strategies on Project and Structural Software Attributes in SOA, On the Move to Meaningful Internet Systems 2005: OTM Workshops, Cyprus, October 11, 2005.

[10] Hein, A, Software Quality and Influence of Size, AOQ Presentation, November 25, 2004.

[11] Paithankar, K. and Ingle, M., Reviewing Software Quality Attributes Classification in Perspective of Usability, to appear in PCTE Journal of Computer Science, Punjab College of Technical Education, Ludhiana, January-July issue 2010. 